\title{
Effect of Ultrasound on the Formation of Parachloroaniline Study in ex-vivo
}

\author{
Yevenes $\mathrm{I}^{1 *}$, Neira $\mathrm{M}^{1}{ }^{1}$, Parada $\mathrm{J}^{2}$, Correa $\mathrm{V}^{3}$ and Araya $\mathrm{P}^{3}$ \\ ${ }^{1}$ Institute for Research in Dental Sciences, University of Chile, Santiago, Chile \\ ${ }^{2}$ Department of Inorganic and Analytical Chemistry, University of Chile, Santiago, Chile \\ ${ }^{3}$ Dental Science Department, Facultad de Odontologia, Universidad Andres Bello, Santiago, Chile
}

${ }^{*}$ Corresponding author: Ismael Yevenes, Sergio Livingstone 943, Independencia, Santiago, Chile, Tel: 056-02-9781718; E-mail: iyevenes@odontologia.uchile.cl

Received date: January 25, 2017; Accepted date: April 13, 2017; Published date: April 17, 2017

Citation: Yevenes I, Neira M, Aliste JP, Correa V, Araya P (2017) Effect of Ultrasound on the Formation of Parachloroaniline Study in ex-vivo. J Clin Exp Orthop 3: 34. doi:10.4172/2471-8416.100034

Copyright: () 2017 Yevenes I, et al. This is an open-access article distributed under the terms of the Creative Commons Attribution License, which permits unrestricted use, distribution, and reproduction in any medium, provided the original author and source are credited.

\section{Abstract}

Background: The use of endodontic ultrasound (EUS) improves the irrigating properties of $5 \% \mathrm{NaOCl}$ and its use on $2 \% \mathrm{CHX}$ accelerates its degradation and production of parachloroanilina (PCA). The objective of this study was to quantify the PCA formed by the use EUS in an endodontic treatment using $5 \% \mathrm{NaClO}$ and $2 \% \mathrm{CHX}$ as irrigators.

Methods and Findings: In ex-vivo study, 30 premolars divided into control and two experimental groups underwent a protocolized endodontic treatment and divided into 13 phases, using $5 \% \mathrm{NaOCl}$ and $2 \%$ chlorhexidine. EUS was used in phases 4,12 and 13 . In phases $5,6,7,9,10$ and $11 \mathrm{NaOCl}$ was quantified by UV spectrophotometry. In phase 12 and 13 its quantified PCA by visible spectrophotometry.

The highest $\mathrm{NaOCl}$ values were found in experimental group No 1 , these values of hypochlorite in all stages are greater than $40 \%$ to those found in the control group. These differences were statistically significant, $p<0.05$. Values found in control group and experimental group No 2 are much smaller and similar to each other. There were no differences between groups, with $p>0.05$.

PCA is found in the three groups, being higher in the experimental group No 1 worth $1.09 \times 10^{-2} \mathrm{mg} / \mathrm{ml}$. The measured values of PCA in experimental group No 2 are inferior to group 1 but much higher than the control group. Between the experimental groups Nos. 1 and 2 and the control group the differences were statistically significant $(p<0.05)$, but between the experimental groups there was no statistical difference with $p>0.05$.

Conclusions: Parachloroaniline was found and quantified in the three groups under study. The highest amount of PCA found is located in the experimental group No 1, where it was activated with endodontic ultrasound on $5 \% \mathrm{NaOCl}$. The maximum amounts of PCA formed could produce immunotoxic type effects.
Keywords: Ultrasound; Parachloroaniline study; Endodontic treatment; Saponification reaction; Parachloroaniline; Chlorhexidine

\section{Introduction}

The ultimate objective of endodontic therapy is the removal of all vital or necrotic tissue, microorganisms, and microbial byproducts from the root canal system. This may be achieved through chemomechanical debridement of root canal. The root canal system is highly complex and variable and has limited our ability to clean and disinfect it predictably. Shaping of root canals is performed almost entirely by using hand and rotary instrumentation techniques [1].

Of all the currently used substances, sodium hypochlorite ( $\mathrm{NaOCl}$ ) appears to be the most ideal, as it covers more of the requirements for endodontic irrigant than any other known compound. Estrela et al. reported that $\mathrm{NaOCl}$ exhibits a balance that acts as an organic and fat solvent degrading fatty acids, transforming them into salts (soap) and glycerol (alcohol), that reduces the surface tension of the remaining solution (saponification reaction) [2].

Possible ways to improve the efficacy of sodium hypochlorite preparations in tissue dissolution are the temperature of the solutions, prolonged working time and ultrasonic activation [3]. One way to increase the effectiveness of low-concentration sodium hypochlorite solutions is to increase their application temperature. The capacity of a $1 \% \mathrm{NaOCl}$ at $45^{\circ} \mathrm{C}$ to dissolve human dental pulps was found to be equal to that of a $5.25 \%$ solution at $20^{\circ} \mathrm{C}[4]$.

The use of ultrasonic agitation increased the effectiveness of $5 \% \mathrm{NaOCl}$ in the apical third of the canal wall as this would accelerate chemical reactions, create cavitational effects, and achieve a superior cleansing action $[5,6]$. If ultrasonic activation of the hypochlorite irrigant is to be used, it appears important to apply the ultrasonic instrument after the canal preparation has been completed. A freely oscillating instrument will cause more 
ultrasound effects in the irrigating solution than a counterpart that binds to canal walls [7].

When a combination of irrigators is used during endodontic therapy, the first irrigant used may not be completely removed from the root canal system before using the next one. As a result, they come in contact with each other and can form various by-products, such as Parachloroaniline (PCA), a toxic precipitate formed by interacting $\mathrm{NaOCl}$ and Chlorhexidine ( $\mathrm{CHX}$ ) $[8,9]$.

$\mathrm{CHX}$ has been recommended as a root canal irrigant because of its broad spectrum antimicrobial action, substantivity and low toxicity. However, CHX's incapacity of tissue dissolution has been pointed out as its major disadvantage. Some attempts have been made to evaluate the activity of $\mathrm{CHX}$ to dissolve organic matter, demonstrating that both preparations of this substance, aqueous solution or gel, were not able to dissolve pulp tissues [10]. 2\% CHX may be a good choice for maximized antibacterial effect at the end of the chemomechanical preparation [11].

As with sodium hypochlorite, heating a chlorhexidine irrigant of lesser concentration could increase its local efficacy in the root canal system while keeping the systemic toxicity low [12]. The CHX molecule itself poses a systemic risk because it can be decomposed into reactive by-products such as PCA $[13,14]$. The PCA is generated by the hydrolysis of $\mathrm{CHX}$ as a function of time, alkaline $\mathrm{pH}$ and heat [13], and the presence of PCA has been detected in solutions of $\mathrm{CHX}[13,14]$. In an in vitro study the visible light spectrophotometry did not allow to identify that the molecule generated when activating the $2 \% \mathrm{CHX}$ with the endodontic ultrasound was Parachloroaniline [15].

The objective of this study was to quantify the amount of PCA formed by the use of endodontic ultrasound in an endodontic treatment using $5 \% \mathrm{NaOCl}$ and $2 \%$ chlorhexidine as irrigators.

\section{Methodology}

\section{Ethical considerations}

Prospective, experimental and ex-vivo explanatory study approved by the Ethics Committee of Human Research of the Faculty of Dentistry of the University of Chile, protocol number FIOUCH 13-015.

\section{Materials for clinical and laboratory procedures}

High speed round diamond stones No. 12 and No. 14 (SS White Burs, Inc. 1145 Towbin Avenue Lakewood, NJ 08701, USA). Round carbide round carbide cutters No. 12 and No. 14 (SS White Burs, Inc. 1145 Towbin Avenue Lakewood, NJ 08701, USA). Endo Z low speed cutters (Dentsply-Maillefer, Chemin du Verger 3, 1338 Ballaigues, Suisse). Strawberries Gates Glidden No. 1-2-3 (MANI, INC. 743 Nakaakutsu, Takanezawa, Shioya, Tochigi 329-1234, Japan). Monoject Irrigation Syringes (Covidien, 15 Hampshire, Mansfield, MA 02048 USA). Kerr Files 1st and 2nd Series (Dentsply-Maillefer, Chemin du Verger 3, 1338 Ballaigues, Suisse). Fermin (DETAX GmbH \& Co. KG, Carl-Zeiss-Str. 476275 Ettlingen, Germany). Self-cured lonomer Glass (Dentsply DeTrey
GmbH 78467, Konstanz, Germany). Eppendorf Tubes $1.5 \mathrm{ml}$ (Biologix Group Limited, No. 2766 Ying Xiu Road, High-Tech Industrial Development Zone Jinan, Shandong 250101 PR China). 100 and 1000 Labopette Micropipettes (Hirschmann, Inc. Holloway Road, Suite 104 Bluegrass Industrial Park, Louisville, KY 40299, USA). Hermle z216 MK Centrifuge (HERMLE Labortechnik GmbH, Siemensstr 25 D-78564, Wehingen, Germany). UNICAM ${ }^{\circledast}$ UV/VIS Spectrophotometer (ThermoSpectronicUnicam UV-530 UV-Visible, Rochester, NY, USA). 1cc quartz cuvettes (Scientech, Inc. 5649 Arapahoe Avenue Boulder, CO 80303-1399, USA).

\section{Reagents for clinical and laboratory procedures}

$5 \%$ Sodium Hypochlorite ( $\mathrm{NaOCl}$, Sigma-Aldrich 3050 Spruce St. St. Louis, MO 63103, USA). 4-Chloroaniline (Sigma-Aldrich, St. Louis, MO, USA). 20\% Chlorhexidine digluconate solution in $\mathrm{H}_{2} \mathrm{O}$ (Sigma-Aldrich, St. Louis, MO., USA). 10\% EDTA (EDTA, Merck Millipore, Frankfurter Str. 250, 64293 Darmstadt, Germany). 0.9\% Sodium Chloride (JT Baker, Mallinckrodt Baker, SA. de C.V. Xalostoc, 55320, Edo de Mex. Mexico, USA). Hydrochloric Acid (J.T.Baker, Mallinckrodt Baker, S.A. de C.V. Xalostoc, 55320, Edo de Mex. Mexico, USA). Sodium Nitrite (Merck Millipore, Frankfurter Str. 250, 64293 Darmstadt, Germany). Ammonium Sulfamate (Sigma-Aldrich ChemieGmbh Munich, Germany). NaftilEthylndiamineDihydrochloride (Sigma-Aldrich 3050 Spruce St. St. Louis, MO 63103, USA). Alcohol 96\% (Merck Millipore, Frankfurter Str. 250, 64293 Darmstadt, Germany).

\section{Endodontic treatment and sampling of treatment phases}

The selection criteria of the samples were healthy uniradicular teeth with medium or wide channel gauges in the three-thirds root analysed on the previous radiograph. The teeth were divided into three groups: one control group $(n=10)$ and two experimental groups of 10 pieces each. The teeth of the control group and experimental groups underwent an endodontic treatment according to the clinical protocol of irrigation of the Faculty of Dentistry of the University of Chile. By aspiration with a device specially designed for this study, the solutions obtained from the root canal were collected during some phases of the treatment.

\section{Flow diagram of the phases of endodontic treatment}

In flow chart (Figure 1) can be identified samples were collected phases 5,6 and 7, which correspond to washes performed with saline, after application of the $5 \% \mathrm{NaOCl}$ in four opportunities (phases 1 to 4). Then the phases 9,10 and 11, which are washed with serum subsequent use of $1 \mathrm{~mL}$ of $10 \%$ EDTA was collected. In all these phases, we quantified $\mathrm{NaOCl}$ present. Phase 12 corresponds to sample collection after use of $2 \% \mathrm{CHX}$ as intracanal medication. The access cavity was sealed with double sealing and the apex was sealed with pink wax, the tooth was placed in physiological serum at $37^{\circ} \mathrm{C}$ for one week. At 7 days the canal was entered. Phase 13 corresponds to the sample collected in the final irrigation of the root canal with $3 \mathrm{~mL}$ of $2 \% \mathrm{CHX}$, prior to obturation (Figure 1 ). 


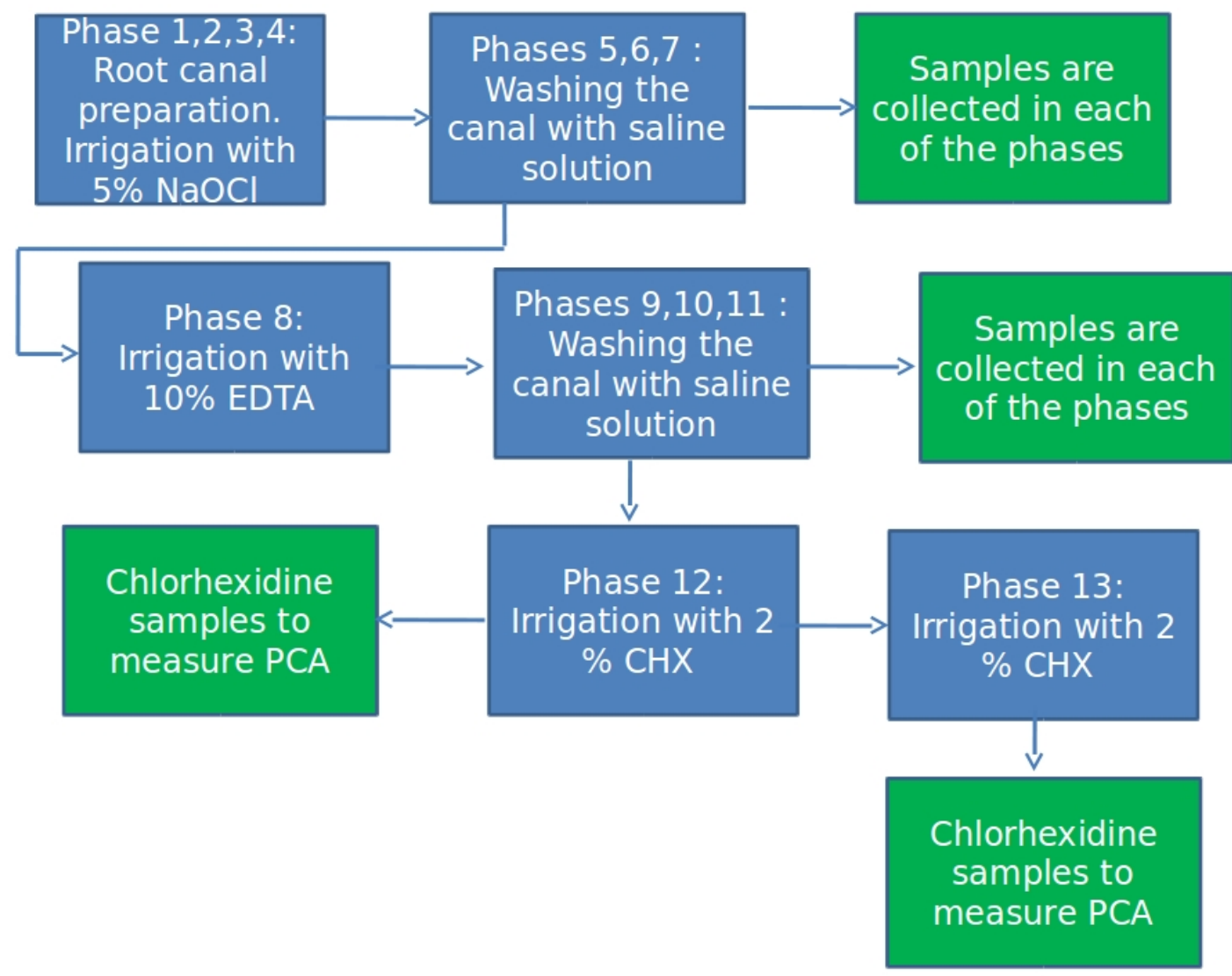

Figure 1: Flow diagram of the phases of endodontic treatment.

\section{Application of endodontic ultrasound}

Endodontic ultrasound was not applied to the control group. To the experimental group No 1, endodontic ultrasound (EUS) was used with MECTRON ${ }^{\circledast}$ Model piezo smart equipment (Mectron spa, Carasco (GE), Italy) at a frequency of 24,500 Hrtz with $a^{\#} 55 \mathrm{~K}$ file of $31 \mathrm{~mm}$ mark KERR -SYBRONEND Model K3 (SybronEndo Corporation, 1717 West Collins Orange, CA 92867) for 60 seconds in phase $4(5 \% \mathrm{NaOCl})$. Experimental group No 2 used EUS for 60 seconds in phases 12 and 13 (2\% CHX).

\section{Analysis of the samples}

Samples collected in phases 5,6,7,9,10,11,12 and 13, for each tooth were transferred to Eppendorf tubes, centrifuged at $10,000 \mathrm{rpm}$ for 5 minutes at $4^{\circ} \mathrm{C}$ and the chemical analysis was carried out.

\section{Determination of $\mathrm{NaOCl}$ concentration}

To determine the $\mathrm{NaOCl}$ concentration, UV spectroscopy was used by reading the absorbance values of the samples at a maximum lambda ( $\lambda \max$ ) of $292 \mathrm{~nm}$. These absorbance values were transformed into concentration by a calibration curve between $0.0005 \%$ and $0.05 \%$ of $\mathrm{NaOCl}$.

\section{Determination of PCA concentration}

The protocol described in the European Pharmacopoeia (2005) modified by Alegre et al. [16]. Visible spectrophotometry was used by reading the colored complex forming the PCA at $552 \mathrm{~nm}$. A calibration curve between $0.00005 \%$ and $0.001 \%$ PCA was constructed to determine the concentration of PCA in the samples collected. The curve equation was obtained, which converts absorbance to PCA concentration.

\section{Statistical analysis}

The data obtained were subjected to the Shapiro-Wilk statistical test to determine the type of distribution. This test showed that the samples had no normal distribution. Data were then submitted to the Mann Whitney test to establish the significance of the differences found using the IBM SPSS statistical software. A 95\% confidence interval was set, accepting statistically significant differences when $p<0.05$.

\section{Results}

Using the samples absorbance and calibration curves, the concentration of $\mathrm{NaOCl}$ and PCA was determined in the different phases of the endodontic treatment under the proposed irrigation protocol. To determine the concentration of sodium hypochlorite in the samples, it was used the equation of the calibration curve: 
$A=15,2393 \times[\mathrm{NaOCl}]-0,032$ with a $R^{2}=0,993165$, where $A$ is absorbance and $R^{2}$ is correlation coefficient. The equation of the curve for determining PCA is:

$$
A=87,6981 \times[P C A]+0,0075 \text { with a } R^{2}=0,994489 \text {. }
$$

The initial concentration of $5 \% \mathrm{NaOCl}$ decreases after the chemical-mechanical preparation of the root canal. For the control group the values of residual sodium hypochlorite in Phase 5 of the endodontic treatment being of the order of $0.01 \%$ (Table 1). Concentration that is diminishing in the following phases by the effect of the lavage with serum. The lowest concentrations of sodium hypochlorite are observed in step 11 with values of the order of $0.002 \%$.

The ultrasound application was made in stage 4 on $5 \%$ sodium hypochlorite (Experimental Group No 1), its effect was measured on residual hypochlorite from steps 5,6,7,9,10 and 11 (Table 1). As it is possible to observe, these values of hypochlorite in all stages are greater than $40 \%$ to those found in the control group. These differences were statistically significant, $p<0.05$ (Table 1 ).

Table 1: Concentrations of sodium hypochlorite measured in the different phases in the three groups of the studio.

\begin{tabular}{|c|c|c|c|c|c|c|}
\hline & \multicolumn{4}{|c|}{ Sodium Hypochlorite ( $\mathrm{NaOCl})$} & & \\
\hline & \multicolumn{2}{|c|}{$\begin{array}{l}\text { Control } \\
\text { Not EUS }\end{array}$} & \multicolumn{2}{|c|}{$\begin{array}{l}\text { Experimental } \\
\text { Group No } 1 \text { EUS } \\
\text { in F4 }\end{array}$} & \multicolumn{2}{|c|}{$\begin{array}{l}\text { Experimental } \\
\text { Group No } 2\end{array}$} \\
\hline & $\begin{array}{l}\text { Mean } \\
\%\end{array}$ & SD & $\begin{array}{l}\text { Mean } \\
\%\end{array}$ & SD & $\begin{array}{l}\text { Mean } \\
\%\end{array}$ & SD \\
\hline $\begin{array}{l}\text { Phase } \\
5\end{array}$ & $\begin{array}{l}0.0090 \\
1\end{array}$ & $\begin{array}{l}0.0077 \\
6\end{array}$ & $\begin{array}{l}0.0131 \\
7\end{array}$ & $\begin{array}{l}0.0074 \\
9\end{array}$ & $\begin{array}{l}0.0095 \\
2\end{array}$ & $\begin{array}{l}0.0024 \\
5\end{array}$ \\
\hline $\begin{array}{l}\text { Phase } \\
6\end{array}$ & $\begin{array}{l}0.0022 \\
8\end{array}$ & $\begin{array}{l}0.0004 \\
7\end{array}$ & $\begin{array}{l}0.0040 \\
7\end{array}$ & $\begin{array}{l}0.0012 \\
8\end{array}$ & $\begin{array}{l}0.0023 \\
4\end{array}$ & $\begin{array}{l}0.0007 \\
4\end{array}$ \\
\hline $\begin{array}{l}\text { Phase } \\
7\end{array}$ & $\begin{array}{l}0.0020 \\
7\end{array}$ & $\begin{array}{l}0.0003 \\
9\end{array}$ & $\begin{array}{l}0.0030 \\
3\end{array}$ & $\begin{array}{l}0.0001 \\
4\end{array}$ & $\begin{array}{l}0.0020 \\
2\end{array}$ & $\begin{array}{l}0.0005 \\
5\end{array}$ \\
\hline $\begin{array}{l}\text { Phase } \\
9\end{array}$ & $\begin{array}{l}0.0018 \\
8\end{array}$ & $\begin{array}{l}0.0002 \\
8\end{array}$ & $\begin{array}{l}0.0029 \\
1\end{array}$ & $\begin{array}{l}0.0004 \\
5\end{array}$ & $\begin{array}{l}0.0019 \\
1\end{array}$ & $\begin{array}{l}0.0007 \\
9\end{array}$ \\
\hline $\begin{array}{l}\text { Phase } \\
10\end{array}$ & $\begin{array}{l}0.0018 \\
7\end{array}$ & $\begin{array}{l}0.0002 \\
4\end{array}$ & $\begin{array}{l}0.0027 \\
6\end{array}$ & $\begin{array}{l}0.0003 \\
5\end{array}$ & $\begin{array}{l}0.0017 \\
4\end{array}$ & $\begin{array}{l}0.0002 \\
7\end{array}$ \\
\hline $\begin{array}{l}\text { Phase } \\
11\end{array}$ & $\begin{array}{l}0.0016 \\
1\end{array}$ & $\begin{array}{l}0.0001 \\
2\end{array}$ & $\begin{array}{l}0.0024 \\
3\end{array}$ & $\begin{array}{l}0.0004 \\
6\end{array}$ & $\begin{array}{l}0.0016 \\
4\end{array}$ & $\begin{array}{l}0.0002 \\
8\end{array}$ \\
\hline
\end{tabular}

The experimental group No 2 corresponds to the application of endodontic ultrasound in stages 12 and 13 , on $2 \%$ chlorhexidine. Residual sodium hypochlorite measurements in this experimental group in stages 5,6,7,9,10 and 11 show values very similar to the control group.There were no differences between groups, with $p>0.05$.

The formation and quantification of parachloroaniline was visualized through the formation of a colored complex and quantified by visible spectrophotometry. Parachloroaniline was found in all three groups of the study and the lowest values of
PCA were found in the control group, with values of $7.5 \times 10^{-4} \%$ and $4.8 \times 10^{-4} \%$ in phases 12 and 13 respectively (Table 2 ).

Table 2: Concentrations of Parachloroaniline (PCA) measured in the in phase 12 and 13 of the endodontic treatment in the three groups of the studio.

\begin{tabular}{|l|l|l|l|l|l|l|}
\hline \multicolumn{4}{|l|}{ Parachloroaniline (PCA) } & \multicolumn{2}{l|}{} \\
\hline & \multicolumn{2}{|l|}{$\begin{array}{l}\text { Control Group Not } \\
\text { EUS }\end{array}$} & \multicolumn{2}{|l|}{$\begin{array}{l}\text { Experimental } \\
\text { Group No 1 EUS } \\
\text { in F4 }\end{array}$} & \multicolumn{2}{l|}{$\begin{array}{l}\text { Experimental } \\
\text { Group No 2 EUS } \\
\text { in F12 and F13 }\end{array}$} \\
\hline & Mean & SD & Mean & SD & Mean & SD \\
\hline $\begin{array}{l}\text { Fase } \\
\mathbf{1 2}\end{array}$ & $\begin{array}{l}0.0007 \\
5\end{array}$ & $\begin{array}{l}0.0001 \\
7\end{array}$ & $\begin{array}{l}0.0010 \\
9\end{array}$ & $\begin{array}{l}0.0002 \\
0\end{array}$ & $\begin{array}{l}0.0010 \\
0\end{array}$ & $\begin{array}{l}0.0001 \\
8\end{array}$ \\
\hline $\begin{array}{l}\text { Fase } \\
\mathbf{1 3}\end{array}$ & $\begin{array}{l}0.0004 \\
8\end{array}$ & $\begin{array}{l}0.0002 \\
3\end{array}$ & $\begin{array}{l}0.0007 \\
7\end{array}$ & $\begin{array}{l}0.0002 \\
2\end{array}$ & $\begin{array}{l}0.0006 \\
2\end{array}$ & 0.0003 \\
\hline
\end{tabular}

The measured values of parachloroaniline in the experimental groups are higher than the control group. The highest measured values were found in experimental group No 1, where endodontic ultrasound was applied in stage 4, with values of $10.9 \times 10^{-4} \%$ and $7.7 \times 10^{-4} \%$ for phases 12 and 13 respectively. Between the experimental groups, Nos. 1 and 2 and the control group the differences were statistically significant $(p<0.05)$, but between the experimental groups there was no statistical difference with $p>0.05$.

\section{Discussion}

Using ultrasonic energy in endodontic treatment has improved treatment quality in many aspects, including access to root canal entry holes, cleaning, shaping and filling the canals, eliminating the obstructions and intracanal materials and endodontic surgery [17].

In active irrigation, the use of ultrasound is integrated with endodontic therapy to increase the removal of detritus and microorganisms, based on the oscillation, cavitation, acoustic microcurrent and heat generation phenomena generated by ultrasound [18].

The generation of heat and temperature increase are effects that produce the application of ultrasound inside the root canal. This results from the energy released during cavitation, with implosion of gas microbubbles or friction generated by contact of the oscillatory file with the walls of the root canal [6].

The average concentration of residual $\mathrm{NaOCl}$ in both the control group and the experimental groups is decreasing using the intermediate irrigant that corresponds to the physiological serum. The serum is used in phases 5 through 7 and 9 through 11. The concentration of residual hypochlorite in endodontic treatments cannot be compared with bibliographic data since there are none. In the control group of our investigation, without USE activation, the residual $\mathrm{NaOCl}$ presented values like those found by Alegre et al. [16], ranging from $6.8 \times 10^{-3} \%$ to 1.3 $\times 10^{-3} \%$ between phase 5 to phase 7 .

The use of endodontic ultrasound through its various mechanisms activates $\mathrm{NaOCl}$, this activation is reflected in 
varied effects on elements present in the root canal system. The literature indicates that EUS increases the antibacterial activity of sodium hypochlorite [19] and improves the removal of bacterial biofilm [20]. In addition, $\mathrm{NaOCl}$ removed the debris and smear layer very effectively [21].

In our results, the effect of EUS is clearly shown in experimental phase 1 , where the $5 \% \mathrm{NaOCl}$ in phase 4 is activated. The measured values of residual $\mathrm{NaOCl}$ in the following phases are much higher than those found in the group control. The possible explanation for this increase in concentration is due to EUS activation, associated with an increase in temperature as well as an increase in the basicity of hypochlorite [15].

Residual sodium hypochlorite measurements in experimental group No. 2 are comparable to those obtained in the control group, where the sodium hypochlorite values in phases 9 to 11 range from $1.9 \times 10^{-3} \%$ to $1.6 \% \times 10^{-3} \%$. This similarity of results can be explained because the EUS effect is applied later and does not affect sodium hypochlorite.

In this investigation, the formation of parachloroaniline can originate in two ways. The first corresponds to the reaction between sodium hypochlorite and chlorhexidine. The association of $\mathrm{NaOCl}$ at different concentrations with $2 \% \mathrm{CHX}$ produces an orange-brown precipitate whose chemical composition is not fully elucidated. The formation of this precipitate can be explained by an acid-base reaction which occurs when $\mathrm{NaOCl}$ and $\mathrm{CHX}$ are mixed together. $\mathrm{CHX}$ is a dicationic acid that has the ability to donate protons, while $\mathrm{NaOC}$ is alkaline and can receive protons from $\mathrm{CHX}$. This exchange of protons produces the formation of a neutral and insoluble substance that precipitates [22]. Basrani et al. concluded that the formation and amount of PCA is directly related to the concentration of $\mathrm{NaOCl}$, with $0.023 \%$ being the lowest concentration at which color change was observed and $0.19 \%$ the minimum at which the precipitate formed [8]. Studies the Bilbao et al. [23] have shown that when mixing $2 \% \mathrm{CHX}$ with aqueous $\mathrm{NaOCl}$ dilutions ranging from $5 \%$ to $0.0005 \%$, the solution changes color in direct relation to the $\mathrm{NaOCl}$ concentration and evidence of PCA formation, which corresponds to results obtained by Basrani et al. [8].

This work shows that there is formation of PCA in both the control and experimental groups. Residual values of $\mathrm{NaOCl}$ measured in the phases prior to the use of $\mathrm{CHX} 2 \%$ in the three groups show us values in phase 11 between $1.6 \times 10^{-3} \%$ and 2.3 $\times 10^{-3} \%$ of $\mathrm{NaOCl}$, values that according to Bilbao et al. [23] are sufficient for there to be PCA training. The highest values of PCA were found in the experimental group No 1, values that in phase 12 are $40 \%$ or higher than the values of the control group. In phase 13 PCA values are lower than those in phase 12 , but the relationship is maintained where the PCA concentration in the experimental group is much higher than in the control group. Undoubtedly, these differences in concentrations of PCA found between experimental group 1 and control are due to differences in concentration of residual sodium hypochlorite between the experimental phase and the control phase. In all phases where sodium hypochlorite was measured, the measured values were always much higher in the experimental groups (Table 1).

The measured values of PCA in phases 12 and 13 are greater in the experimental group No 2 than those found in the control group, but lower than the values of the experimental group No 1. To explain this increase in the concentration of PCA, the effect of the use of USE in these phases on $2 \% \mathrm{CHX}$ is validated, this corresponds to the second route in the process of formation of PCA in this publication. Literature reports that $\mathrm{CHX}$ can spontaneously hydrolyze and form PCA in the presence of heat, light and alkaline environment and that by increasing the $\mathrm{CHX}$ temperature above $45^{\circ} \mathrm{C}$ PCA is produced as a by-product, therefore, the use of $\mathrm{CHX}$ and ultrasound should not be combined [8]. Barbin et al. (2013), detected PCA in 2\% CHX solutions that were stored for 7 days under conditions of $95 \%$ relative humidity and $36.5^{\circ} \mathrm{C}$ [24].

A study by Onetto et al. in vitro on the effect of endodontic ultrasound on $2 \% \mathrm{CHX}$ found that EUS increases $2 \% \mathrm{CHX}$ temperature at $1^{\circ} \mathrm{C}$ independent of time and acidifies its $\mathrm{pH}$. No presence of PCA was detected by visible spectrophotometry. Absorption spectrums of $2 \% \mathrm{CHX}$ activated with EUS at different times presented differences between them and with $2 \% \mathrm{CHX}$ unactivated, these differences would indicate degradation of CHX and appearance of PCA. Our study carried out in ex-vivo, with a more sensitive methodology to measure PCA, it was possible to find and quantify PCA formed by endodontic ultrasound effect [15].

The toxic effects of PCA are at concentrations of 1.0 to 0.1 $\mathrm{mg} / \mathrm{ml}$, and immunotoxic effects at concentrations of 0.01 to $0.001 \mathrm{mg} / \mathrm{ml}$, these concentrations being 10-100 times lower than which give rise to toxic effects [25]. In our study, the maximum value found for PCA was in the experimental group No. 2 in phase 12 and had a value of $1.09 \times 10^{-2} \mathrm{mg} / \mathrm{ml}$, a value that according to the bibliographic information would not produce toxic effects but if possible immunotoxic effects.

\section{Conclusions}

Parachloroaniline was found and quantified in the three groups under study. The highest amount of PCA found is located in the experimental group No. 1, where it was activated with endodontic ultrasound on $5 \% \mathrm{NaOCl}$. The maximum amounts of PCA formed could produce immunotoxic type effects.

\section{References}

1. Paque F, Ganahl D, Peters OA (2009) Effects of root canal preparation on apical geometry assessed by micro-computed tomography. J Endod 35: 1056-1059.

2. Estrela C, Cyntia RA. Estrela, Barbin EL, César J, Spanó E, et al. (2002) Mechanism of action of sodium hypochlorite. Braz Dent J 13: 113-117.

3. Zehnder M (2006) Root canal irrigants. J Endod 32: 389-398.

4. Sirtes G, Waltimo T, Schaetzle M, Zehnder M (2005) The effects of temperature on sodium hypochlorite short-term stability, pulp dissolution capacity, and antimicrobial efficacy. J Endod 31: 669-671. 
5. Paragliola R, Franco V, Fabiani C, Mazzoni A, Nato F, et al. (2010) Final Rinse Optimization: Influence of Different Agitation Protocols. J Endod 36: 282-285.

6. Martin H (1976) Ultrasonic disinfection of the root canal. Oral Surg Oral Med Oral Pathol 42: 92-99.

7. Roy RA, Ahmad M, Crum LA (1994) Physical mechanisms governing the hydrodynamic response of an oscillating ultrasonic file. Int Endod J 27: 197-207.

8. Basrani BR, Manek S, Sodhi R, Fillery E, Manzur A (2007) Interaction between sodium hypoclorite and clorhexidine gluconate. J Endod 33: 966-969.

9. Rasimick BJ, Nekich M, Hladek MM, Musikant BL, Deutsch AS (2008) Interaction between Chlorhexidine Digluconate and EDTA. J Endod 34: 1521-1523.

10. Gomes PFA (2013) Chlorhexidine in Endodontics. Braz Dent J 24 89-102.

11. Russell AD, Day MJ (1993) Antibacterial activity of chlorhexidine. J Hosp Infect 25: 229-238.

12. Babich H, Wurzburger BJ, Rubin YL, Sinensky MC, Blau L (1995) An in vitro study on the cytotoxicity of chlorhexidine digluconate to human gingival cells. Cell Biol Toxicol 11: 79-88.

13. Havlîková L, Matysová L, Novâková L, Hájková R, Solich $\mathrm{P}$, et al. (2007) HPLC determination of chlorhexidine gluconate and $p$ chloroaniline in topical ointment. J Pharm Biomed Anal 43: 1169-1173.

14. Usui K, Hishinuma T, Yamaguchi H, Tachiirib N, Goto J, et al. (2006) Determination of chlorhexidine (CHD) and nonylphenolethoxylates (NPEOn) using LC-ESI-MS method and application to hemolyzed blood. J Chromatogr B 831: 105-109.

15. Onetto D, Correa V, Araya P, Yévenes I, Neira M (2015) Efecto de ultrasonido endodóntico sobre clorhexidina al $2 \%$ en la formación de paracloroanilina: Estudio in vitro. Rev Clin Periodoncia Implantol Rehabil Oral 8: 185-191.

16. Alegre O, Yévenes I, Maggiolo S, Parada J (2014) Determinación del contenido residual de paracloroanilina ex vivo producido en tratamiento endodóntico tras la utilización de hipoclorito de sodio al $5 \%$ y clorhexidina $2 \%$. Facultad de Odontología, Universidad de Chile.

17. Plotino G, Pameijer CH, Grande NM, Somma F (2007) Ultrasonics in endodontics: a review of the literature. J Endod 33: 81-95.

18. De Paolis G, Vicenti V, Prencipe M, Milana V, Plotino G (2010) Ultrasonics in endodontic surgery: a review of the literature. Ann Stomatol 1: 6-10.

19. Briseño M, Wirth R, Hamm G, Standhartfnger W (1992) Efficacy of different irrigation methods and concentrations of root canal irrigation solution son bacteria in the root canal. Endod Dent Traumatol 8: 6-11.

20. Bhardwaj A, Velmurugan N, Ballal S (2013) Efficacy of passive ultrasonic irrigation with natural irrigants (Morinda citrifolia juice, Aloe Vera and Propolis) in comparison with $1 \%$ sodium hypochlorite for removal of E. faecalis biofilm: An in vitro study. Indian J Dent Res 24: 35.

21. Ahmad M, Ford TRP, Crum LA (1987) Ultrasonic debridement of root canals: acoustic streaming and its possible role. J Endod 13: 490-499.

22. Mohammadi Z, Abbott PV (2009) The properties and applications of chlorhexidine in endodontics. Int Endod J 42: 288-230.

23. Bilbao M, Maggiolo S, Neira M, Yévenes I (2017) Saline Solution in the Formation of Para-Chloroaniline in the Reaction between Chlorhexidine and Sodium Hypochlorite". EC Dental Science 8: 219-226.

24. Barbin LE, Estrela C, Guedes DF, Spanó JC, Sousa-Neto MD, et al. (2013) Detection of para-chloroaniline, reactive oxygen species, and 1-chloro-4 nitrobenzene in high concentrations of chlorhexidine and in a mixture of chlorhexidine and calcium hydroxide. J Endod 39: 664-668.

25. Barbin LE, Saquy PC, Guedes DFC, Sousa-Neto MD, Estrela C, et al. (2008) Determination of para-chloroaniline and reactive oxygen species in chlorhexidine and chlorhexidine associated with calcium hydroxide. J Endod 34: 1508-1514. 